\title{
Phenotypic and Molecular Detection of IMP and SPM Metallo-Beta-Lactamases in Clinical Isolates of Carbapenem Resistant Pseudomonas aeruginosa
}

\author{
Zahra Norouzi Bazgir \\ Mazandaran University of Medical Sciences \\ Mohammad Ahanjan \\ Mazandaran University of Medical Sciences \\ Hamid Reza Goli ( $\sim$ goli59@gmail.com )

\section{Roya Ghasemian} \\ Mazandaran University of Medical Sciences \\ Mohammad Bagher Hashemi-Soteh \\ Mazandaran University of Medical Sciences
}

Mazandaran University of Medical Sciences https://orcid.org/0000-0002-2932-1911

\section{Research note}

Keywords: Pseudomonas aeruginosa, Carbapenem, Metallo-beta-lactamase, Combined Disc Test, IMP, SPM

Posted Date: September 10th, 2020

DOI: https://doi.org/10.21203/rs.3.rs-60519/v1

License: (c) (1) This work is licensed under a Creative Commons Attribution 4.0 International License. Read Full License 


\section{Abstract}

Objectives: Metallo-beta-lactamases play a major role in the resistance of Pseudomonas aeruginosa to carbapenems. The aim of this study was the phenotypic and molecular detection of IMP and SPM carbapenemase genes in 100 carbapenem-resistant clinical isolates of $P$. aeruginosa. The isolates identified using standard microbiological tests, and their antibiotic susceptibility pattern determined by disk agar diffusion (Kirby Bauer) method. Phenotypic identification of Metallo-beta-lactamase-producing strains assessed by the combined disk test (CDT). Then, PCR was used to detect the presence of IMP and SPM genes.

Results: The highest and lowest levels of antibiotic resistance were observed against gentamicin (40\%) and piperacillin-tazobactam (13\%), respectively. Besides, 40 isolates (40\%) had the Multi-drug Resistant (MDR) phenotype, while 5 (12.5\%) MDR isolates were resistant to all antibiotics tested. The results of the CDT showed that among 43 carbapenem non-susceptible clinical isolates of $P$. aeruginosa, $33(76.74 \%)$ isolates were Metallo-betalactamase-producing strains. Also, the frequency of the IMP gene was determined to be $9 \%$, while none of these isolates carried the SPM gene. Due to the high prevalence of carbapenem-resistant and MDR $P$. aeruginosa in this study, routine antibiotic susceptibility testing and phenotypic identification of carbapenemase production by this bacterium are necessary for proper selection of antibiotics.

\section{Introduction}

Pseudomonas aeruginosa is an important opportunistic gram-negative pathogen causing almost $10 \%$ of nosocomial infections worldwide such as urinary tract infections, bacteremia, sepsis, and pneumonia in immunocompromised patients, especially in intensive care units (ICUs), as well as cystic fibrosis and burned patients $(1-3)$. Today, one of the most important complications related to this bacterium in developing countries is the emergence of multidrug resistant strains (4). Carbapenems are the last line treatment option for the infections caused by this bacterium, but recently resistance to carbapenems has been increased resulting to high mortality, especially in immunocompromised patients (5). Decreased expression of outer membrane proteins, increased expression of efflux systems, and secretion of beta-lactamases are the most important mechanisms of antibiotic resistance in clinical isolates of $P$. aeruginosa (6). One of the most important mechanisms of carbapenem resistance in $P$. aeruginosa is the production of Metallo-beta-lactamases (MBLs). These enzymes belonged to the class $B$ beta-lactamases requiring the zinc for activity and can hydrolyze a wide range of beta-lactamases $(6,7)$. MBL-producing $P$. aeruginosa first reported in 1991 in Japan (8). The MBLs can hydrolyze penicillins and cephalosporins, and their encoding genes are often propagated horizontally among Gram-negative bacteria due to the presence of mobile genetic elements such as transposons and integrons $(6,9)$. The IMP (Imipenemase) and SPM (Sao Paulo Metallo-beta-lactamase) genes are the most clinically common MBLs (8). The SPM gene first identified in $P$. aeruginosa isolated from a blood culture sample of a 4-year-old girl with leukemia in Brazil (10), and the IMP gene first identified in Japan (6). Prompt diagnosis and accurate reporting of the presence of these genes in hospitals can lead to better and more effective control of carbapenem-resistant strains and eradication of nosocomial infections. Therefore, due to the importance of the presence of Metallo-beta-lactamases in $P$. aeruginosa, this study aimed to phenotypic identify MBLs and molecular assessment of the presence of IMP and $S P M$ genes in the clinical isolates of carbapenem-resistant $P$. aeruginosa in teaching and treatment hospitals of Mazandaran province, north of Iran.

\section{Materials And Methods}




\section{Patients and bacterial isolates}

In this descriptive-analytical study, 100 non-repetitive Pseudomonas aeruginosa isolated from different clinical samples collected from hospitalized and outpatients from May 2018 to June 2019. The clinical isolates identified using standard microbiological methods and biochemical tests (3) and confirmed by the API (Analytical Profile Index) kit (France, BioMérieux, Lyon).

\section{Antibiotic susceptibility testing}

The antibiotic susceptibility pattern of the isolates was determined by the disk agar diffusion method (Kirby-Bauer) according to the instructions of the Clinical and Laboratory Standards Institute (CLSI) (11). In this test, we used the Pseudomonas aeruginosa ATCC 27853 as the control strain. The antibiotics studied included imipenem (10 $\mu \mathrm{g})$, meropenem $(10 \mu \mathrm{g})$, doripenem $(10 \mu \mathrm{g})$, ceftazidime $(30 \mu \mathrm{g})$, Aztreonam $(30 \mu \mathrm{g})$, piperacillin-tazobactam (100 $10 \mu \mathrm{g})$, ciprofloxacin $(5 \mu \mathrm{g})$, and gentamicin $(10 \mu \mathrm{g})$ (MAST Diagnostic Co., UK). Also, the agar dilution test used to investigate the susceptibility pattern of the clinical isolates against colistin according to the instructions of the Clinical and Laboratory Standards Institute (CLSI) (11). Pseudomonas aeruginosa ATCC 27853 chosen as the control strain in this test.

\section{Phenotypic identification of Metallo-beta-lactamase producing strains}

Combined Disk Test (CDT), using imipenem (10 $\mu \mathrm{g})$ alone and imipenem-EDTA $(10-750 \mu \mathrm{g})$, was used to phenotypic detection of the presence of MBLs in clinical isolates of $P$. aeruginosa. An increase in the diameter of the growth inhibition zone greater than or equal to $7 \mathrm{~mm}$ around the imipenem-EDTA combined disk compared to the imipenem disk alone indicates the production of MBLs in this test (12).

\section{Extraction of the bacterial genome and amplification of the IMP and SPM genes by PCR}

The genomic DNAs of $P$. aeruginosa isolates extracted by DNA extraction kit (Bioneer, South Korea). Amplification of the IMP and SPM genes using specific primers as IMP-F:GAAGGCGTTTATGTTCATAC, IMPR:GTATGTTTCAAGAGTGATGC (13), and SPM-F:AAAATCTGGGTACGCAAACG, SPM-R:ACATTATCCGCTGGAACAGG (14) done by thermocycler (Bio-Rad, USA). The condition of the PCR tests was as follows: initial denaturation at $94{ }^{\circ} \mathrm{C}$ for 2 minutes, and 30 cycles including denaturation at $94^{\circ} \mathrm{C}$ for 30 seconds, annealing of the primers at $57{ }^{\circ} \mathrm{C}$ for 30 seconds, and extension of the DNA fragments at $72^{\circ} \mathrm{C}$ for 45 seconds, and a final extension of the fragments at $72{ }^{\circ} \mathrm{C}$ for 10 minutes.

\section{Results}

\section{Patients and bacterial isolates}

Among 100 Pseudomonas aeruginosa clinical isolates in this study, 61 of them collected from men. The age of the patients varied from a few days old to 91 years old, and the mean age range of the patients was $48.65 \pm 13.13$. Also, the ICU with 40 cases had the highest frequency of the isolates (Table 1), while 29, 26, 20, and 11 isolates collected from urine, sputum, wound, and other clinical samples, respectively. Besides, 14 isolates were related to outpatients, while the highest positive culture (71.4\%) among outpatients belonged to the urine samples (Table 1). 
Table 1

Frequency distribution of collected Pseudomonas aeruginosa isolates in terms of hospital ward and type of clinical sample

\begin{tabular}{|c|c|c|c|c|c|c|c|c|c|}
\hline \multirow{2}{*}{$\begin{array}{l}\text { Hospital } \\
\text { wards }\end{array}$} & \multicolumn{9}{|c|}{ No. (\%) of positive culture for Pseudomonas aeruginosa } \\
\hline & Stool & $\begin{array}{l}\text { Plantar } \\
\text { secretion }\end{array}$ & $\begin{array}{l}\text { Eye } \\
\text { secretion }\end{array}$ & Trachea & Catheter & Blood & Sputum & Urine & Wound \\
\hline $\begin{array}{l}\text { ICU } \\
(n=40)\end{array}$ & $\begin{array}{l}1 \\
(2.5)\end{array}$ & - & - & $1(2.5)$ & $3(7.5)$ & - & $22(55)$ & $\begin{array}{l}9 \\
(22.5)\end{array}$ & $4(10)$ \\
\hline $\begin{array}{l}\text { PICU } \\
(n=2)\end{array}$ & - & - & - & $1(50)$ & - & & - & - & $1(50)$ \\
\hline $\begin{array}{l}\text { NICU } \\
(n=1)\end{array}$ & - & - & - & - & - & $\begin{array}{l}1 \\
(100)\end{array}$ & - & - & - \\
\hline $\begin{array}{l}\text { BICU } \\
(n=3)\end{array}$ & - & - & - & - & - & $\begin{array}{l}1 \\
(33.3)\end{array}$ & - & - & $\begin{array}{l}2 \\
(66.6)\end{array}$ \\
\hline $\begin{array}{l}\text { CCU } \\
(n=6)\end{array}$ & - & - & - & - & - & & - & $\begin{array}{l}2 \\
(33.3)\end{array}$ & $\begin{array}{l}4 \\
(66.6)\end{array}$ \\
\hline $\begin{array}{l}\text { Internal } \\
\text { medicine } \\
(n=4)\end{array}$ & - & - & - & - & $1(25)$ & $1(25)$ & - & $2(50)$ & - \\
\hline $\begin{array}{l}\text { Pediatrics } \\
(n=6)\end{array}$ & - & - & 2 (33.33) & 1 (16.6) & - & - & - & $3(50)$ & - \\
\hline $\begin{array}{l}\text { Women } \\
(n=2)\end{array}$ & - & - & - & $1(50)$ & - & - & $1(50)$ & & - \\
\hline $\begin{array}{l}\text { Men } \\
(n=4)\end{array}$ & - & $1(25)$ & - & - & $1(25)$ & $2(50)$ & - & - & - \\
\hline $\begin{array}{l}\text { Surgery } \\
(n=7)\end{array}$ & - & - & - & - & 4 (57.1) & - & & $\begin{array}{l}1 \\
(14.2)\end{array}$ & $\begin{array}{l}2 \\
(28.5)\end{array}$ \\
\hline $\begin{array}{l}\text { Neurology } \\
(n=4)\end{array}$ & - & - & - & - & - & - & $2(50)$ & $2(50)$ & - \\
\hline $\begin{array}{l}\text { Burn } \\
(n=6)\end{array}$ & - & - & - & - & - & $\begin{array}{l}1 \\
(16.6)\end{array}$ & - & - & $\begin{array}{l}5 \\
(83.3)\end{array}$ \\
\hline $\begin{array}{l}\text { Oncology } \\
(n=1)\end{array}$ & - & & - & - & - & - & $1(100)$ & & \\
\hline
\end{tabular}

Abbreviations: ICU; Intensive Care Unit, CCU; Cardiac care unit, NICU; Neonatal Intensive Care Unit (NICU), PICU; Pediatric Intensive Care Unit, BICU; Burnt Intensive Care Unit 


\begin{tabular}{|c|c|c|c|c|c|c|c|c|c|}
\hline \multirow{2}{*}{$\begin{array}{l}\text { Hospital } \\
\text { wards }\end{array}$} & \multicolumn{9}{|c|}{ No. (\%) of positive culture for Pseudomonas aeruginosa } \\
\hline & Stool & $\begin{array}{l}\text { Plantar } \\
\text { secretion }\end{array}$ & $\begin{array}{l}\text { Eye } \\
\text { secretion }\end{array}$ & Trachea & Catheter & Blood & Sputum & Urine & Wound \\
\hline $\begin{array}{l}\text { Outpatient } \\
(n=14)\end{array}$ & $\begin{array}{l}1 \\
(7.1)\end{array}$ & - & - & - & - & $\begin{array}{l}1 \\
(7.1)\end{array}$ & - & $\begin{array}{l}10 \\
(71.4)\end{array}$ & $\begin{array}{l}2 \\
(14.2)\end{array}$ \\
\hline Total & 2 & 1 & 2 & 4 & 9 & 7 & 26 & 29 & 20 \\
\hline
\end{tabular}

\section{Antimicrobial susceptibility testing}

The highest resistance rate (40\%) in the present study related to gentamicin and the lowest resistance (13\%) observed against piperacillin-tazobactam (Table 2). Also, according to the results of the agar dilution test, 26 (26\%) isolates were resistant to colistin, of which 22 (84.6\%), 1 (3.8), 1 (3.8), 1 (3.8), and 1 (3.8) isolates had a MIC = 4, 8, 16,32 , and $256 \mu \mathrm{g} / \mathrm{ml}$, respectively. However, 40 isolates (40\%) shown the Multi-drug Resistance (MDR) phenotype, from which $26(65 \%)$ isolates collected from male patients. Also, 5 (12.5\%) MDR isolates were resistant to all antibiotics tested in this study. Regarding the type of clinical samples, the highest prevalence of MDR strains (27.5\%) observed in bacteria isolated from sputum. In addition, the highest rate of antibiotic resistance among MDR isolates observed against gentamicin, while 38 (95\%) isolates were resistant to this antibiotic. On the other hand, the highest antibiotic resistance observed in wound and catheter isolates, while $P$. aeruginosa isolated from feces and plantar secretions were resistant to all tested antibiotics. Also, only resistance to carbapenems was observed among the tracheal isolates of $P$. aeruginosa (Table 5).

Table 2

Antibiotic susceptibility pattern of 100 Pseudomonas aeruginosa clinical isolates

\begin{tabular}{|llll|}
\hline Antibiotics & Resistant & Intermediate Resistant & Susceptible \\
& $\%$ & $\%$ & $\%$ \\
\hline Imipenem & 28 & 8 & 64 \\
\hline Meropenem & 34 & 7 & 59 \\
\hline Doripenem & 28 & 13 & 59 \\
\hline Piperacillin-tazobactam & 13 & 10 & 77 \\
\hline Cefotaxime & 24 & 2 & 74 \\
\hline Aztreonam & 39 & 23 & 38 \\
\hline Gentamicin & 40 & 2 & 58 \\
\hline Ciprofloxacin & 38 & 4 & 58 \\
\hline
\end{tabular}


Table 3

Antibiotic resistance pattern of Pseudomonas aeruginosa clinical isolates based on sample type

\begin{tabular}{|c|c|c|c|c|c|c|c|c|c|}
\hline \multirow[t]{2}{*}{ Antibiotics } & \multicolumn{9}{|c|}{ No. (\%) of antibiotic resistant Pseudomonas aeruginosa isolated from } \\
\hline & $\begin{array}{l}\text { Stool } \\
(n= \\
2)\end{array}$ & $\begin{array}{l}\text { Plantar } \\
\text { secretion } \\
(n=1)\end{array}$ & $\begin{array}{l}\text { Eye } \\
\text { secretion } \\
(n=1)\end{array}$ & $\begin{array}{l}\text { Trachea } \\
(n=4)\end{array}$ & $\begin{array}{l}\text { Catheter } \\
(n=9)\end{array}$ & $\begin{array}{l}\text { Blood } \\
(n= \\
7)\end{array}$ & $\begin{array}{l}\text { Sputum } \\
(n=26)\end{array}$ & $\begin{array}{l}\text { Urine } \\
(n= \\
29)\end{array}$ & $\begin{array}{l}\text { Wound } \\
(n= \\
20)\end{array}$ \\
\hline Imipenem & - & - & $\begin{array}{l}1 \\
(100)\end{array}$ & $\begin{array}{l}3 \\
(75)\end{array}$ & $\begin{array}{l}4 \\
(44.4)\end{array}$ & $\begin{array}{l}2 \\
(28.5)\end{array}$ & $\begin{array}{l}6 \\
(23.07)\end{array}$ & $\begin{array}{l}4 \\
(13.7)\end{array}$ & $\begin{array}{l}8 \\
(40)\end{array}$ \\
\hline Meropenem & - & - & $\begin{array}{l}1 \\
(100)\end{array}$ & $\begin{array}{l}2 \\
(50)\end{array}$ & $\begin{array}{l}6 \\
(66.6)\end{array}$ & $\begin{array}{l}2 \\
(28.5)\end{array}$ & $\begin{array}{l}10 \\
(38.4)\end{array}$ & $\begin{array}{l}3 \\
(10.3)\end{array}$ & $\begin{array}{l}10 \\
(50)\end{array}$ \\
\hline Doripenem & - & - & $\begin{array}{l}1 \\
(100)\end{array}$ & $\begin{array}{l}2 \\
(50)\end{array}$ & $\begin{array}{l}5 \\
(55.5)\end{array}$ & $\begin{array}{l}2 \\
(28.5)\end{array}$ & $\begin{array}{l}5 \\
(19.2)\end{array}$ & $\begin{array}{l}4 \\
(13.7)\end{array}$ & $\begin{array}{l}9 \\
(45)\end{array}$ \\
\hline $\begin{array}{l}\text { Piperacillin- } \\
\text { tazobactam }\end{array}$ & - & - & & - & $\begin{array}{l}3 \\
(33.3)\end{array}$ & $\begin{array}{l}1 \\
(14.2)\end{array}$ & $\begin{array}{l}3 \\
(11.5)\end{array}$ & $\begin{array}{l}3 \\
(10.3)\end{array}$ & $\begin{array}{l}3 \\
(15)\end{array}$ \\
\hline Cefotaxime & - & - & $\begin{array}{l}1 \\
(100)\end{array}$ & - & $\begin{array}{l}4 \\
(44.4)\end{array}$ & - & $\begin{array}{l}7 \\
(26.9)\end{array}$ & $\begin{array}{l}7 \\
(24.1)\end{array}$ & $\begin{array}{l}5 \\
(25)\end{array}$ \\
\hline Aztreonam & - & - & $\begin{array}{l}1 \\
(100)\end{array}$ & - & $\begin{array}{l}4 \\
(44.4)\end{array}$ & $\begin{array}{l}3 \\
(42.8)\end{array}$ & $\begin{array}{l}10 \\
(38.4)\end{array}$ & $\begin{array}{l}9 \\
(31.03)\end{array}$ & $\begin{array}{l}12 \\
(60)\end{array}$ \\
\hline Gentamicin & - & - & $\begin{array}{l}1 \\
(100)\end{array}$ & - & $\begin{array}{l}6 \\
(66.6)\end{array}$ & $\begin{array}{l}3 \\
(42.8)\end{array}$ & $\begin{array}{l}10 \\
(38.4)\end{array}$ & $\begin{array}{l}10 \\
(34.4)\end{array}$ & $\begin{array}{l}10 \\
(50)\end{array}$ \\
\hline Ciprofloxacin & - & - & $\begin{array}{l}1 \\
(100)\end{array}$ & - & $\begin{array}{l}5 \\
(55.5)\end{array}$ & $\begin{array}{l}3 \\
(42.8)\end{array}$ & $\begin{array}{l}8 \\
(30.7)\end{array}$ & $\begin{array}{l}9 \\
(31.03)\end{array}$ & $\begin{array}{l}12 \\
(60)\end{array}$ \\
\hline
\end{tabular}

\section{Combined Disk Test and PCR}

Using the phenotypic method (CDT), among 43 non-susceptible $P$. aeruginosa isolates (resistant or intermediate resistant) to at least one of the carbapenems (imipenem, meropenem or doripenem), 33 (76.74\%) isolates detected as MBL-producer. Also, regarding sample types, $1 / 2$ (50\%), 2/4 (50\%), 5/9 (55.5\%), 2/7 (28.5\%), 9/26 (34.6\%), 3/29 (10.3\%), and 11/20 (55\%) of the P. aeruginosa isolated from eye secretion, trachea, catheters, blood, sputum, urine, and wounds were CDT positive, respectively. Moreover, out of 14 outpatients, $2(14.2 \%)$ isolates showed a CDT positive result. Based on the hospital wards, $14(35 \%), 1(100 \%)$, and $2(66.6 \%)$ isolates collected from ICU, NICU, and BICU had a positive combined disk test. However, none of the PICU, CCU, and oncology isolates were CDT positive, while $2 / 4$ (50\%), $2 / 6(33.3 \%), 1 / 2(50 \%), 3 / 7(42.8 \%), 2 / 4(50 \%), 1 / 4(25 \%)$, and $3 / 6(50 \%)$ of the $P$. aeruginosa isolated from Internal Medicine, Pediatrics, Women, Surgery, Neurology, Men, and Burn wards detected as CDT positive isolates, respectively. 
On the other hand, the results of the PCR test showed that among 43 carbapenem non-susceptible isolates, only 3 (6.97\%) isolates contained the IMP gene (Figure S1), while none of the isolates carried SPM gene (Figure S2).

All three isolates carrying the IMP gene were resistant to meropenem and doripenem, while 2 (66.6\%) isolates carrying the gene were resistant towards imipenem. On the other hand, 1 (33.3\%) IMP positive isolate detected as resistant against aztreonam as well as piperacillin/tazobactam. Interestingly, all three isolates carrying this gene showed resistance to ceftazidime and gentamicin, while resistance against ciprofloxacin was observed in $2(66.6 \%)$ IMP containing isolates.

\section{Discussion}

The production of carbapenem hydrolyzing enzymes as well as producing a polysaccharide matrix in respiratory infections is one of the most significant mechanisms for resistance to carbapenems in $P$. aeruginosa strains (14, 15). However, not only the sputum isolates of this study were resistant to all antibiotics tested, but also 11 (42.3\%) of them were detected as MDR. On the other hand, our clinical isolates had a relatively low resistance rate $(<40 \%)$ against all antibiotics tested, except gentamicin, as well as other Iranian studies $(3,16)$. However, the studies conducted by Radan et al. in 2016, and Mirsalehian et al. in 2017, reported the higher antibiotic resistance rate (5, 13), may be due to the type of samples, as all isolates collected from burn sections. Since patients with burns may be exposed to broad-spectrum antibiotics pressure, high antibiotic resistance rate observes in these wards (13). In another study conducted in Hamedan, as in our study, the lowest antibiotic resistance of the $P$. aeruginosa clinical isolates was reported against piperacillin-tazobactam (17). It seems that this antibiotic is still one of the effective drugs against this bacterium in Iran.

In the present study, the resistance rate against imipenem (28\%) was similar to other studies in Iran $(6,18)$. On the other hand, the resistance towards imipenem and doripenem in the present study was less than meropenem. According to our assessment, the use of meropenem for the treatment of infections caused by this bacterium in our investigated hospitals was more than imipenem, while the doripenem is not widely used in the treatment of these infections. In another Iranian study conducted in 2017, the resistance to imipenem (8.4\%) and meropenem (9.5\%) was higher than that of penicillin (7.4\%) (3). Also, in some studies, colistin has reported as an effective drug against multidrug-resistant as well as carbapenem-resistant $P$. aeruginosa (13), while $26 \%$ of our isolates detected as colistin-resistant. However, 8 (20\%) MDR isolates in our study were resistant to colistin. The rate of colistinresistance in clinical isolates of $P$. aeruginosa in other studies conducted in Iran and Iraq have reported as $11 \%$ and $18.2 \%$, respectively $(17,19)$.

In the present study, out of 43 carbapenem-resistant isolates, 33 (76.74\%) isolates were CDT positive consistent with some studies conducted in Iran and other countries $(12,20)$. According to the recent studies, we are witnessing an increasing prevalence of MBLs in clinical isolates of $P$. aeruginosa. The rate of MBLs in Kerman was negative in 2008 (21), while in 2015, it was $48 \%$ in Isfahan (7), however, in another study conducted in India, $37.5 \%$ of the $P$. aeruginosa clinical isolates have reported as MBL-producer (22). IMP is one of the most important Metallo-betalactamases causing resistance to beta-lactams and carbapenems (23), whereas in this study, all three isolates carrying the IMP gene were resistant to the carbapenems. In an Iranian study conducted in $2019,4.7 \%$ of the isolates contained the IMP gene (6), while in another study conducted in India, out of all CDT positive isolates, $3 \%$ of them were carrying the IMP gene (20). Studies in Asian, African, and North American countries such as South Korea, India, Egypt, and Canada $(9,20,24,25)$ have reported an IMP gene prevalence of between 2 and $8 \%$, indicating that the prevalence of this gene is low as well as our results.

Page $7 / 11$ 
On the other hand, some studies in Iran and other countries reported no SPM positive $P$. aeruginosa $(7,8,26)$, however, Azimi et al. in 2018 reported a prevalence of $5.6 \%$ and $15.6 \%$ of the SPM and IMP gene, respectively, while all of their isolates collected from children admitted to the burn ward (27). The absence of the SPM gene and the low prevalence of the IMP gene in this study indicate that other mechanisms such as increased expression of efflux pumps, decreased expression of outer membrane proteins, and production of other carbapenemases may have involved in the development of carbapenem-resistant strains in this region. Considering the importance of carbapenem-resistant, colistin-resistant, and MDR isolates of Pseudomonas aeruginosa, routine antibiotic susceptibility testing and using more modern phenotypic tests such as Modified Hodge test and CarbaNP test are essential for the initial identification of carbapenemase-producing $P$. aeruginosa.

\section{Limitations}

The present study had some limitations. Lack of information about other carbapenemase encoding genes belonging to MBL group and genetic relationship between the resistant strains are not determined.

\section{Abbreviations}

IMP: Imipenemase; SPM: Sao Paulo Metalo-betalactamase; CDT: Combined Disk Test; MDR: Multi-drug Resistant; ICU: Intensive Care Unit; MBL: Metallo-beta-lactamase; TSI: Triple Sugar Iron; OF: Oxidation/Fermentation; MR: Methyl Red; VP: Voges Proskauer; API: Analytical Profile Index; CLSI: Clinical and Laboratory Standards Institute; ATCC: American Type Culture Collection: MIC: Minimum Inhibitory Concentration; EDTA: Ethylenediamine Tetraacetic Acid; PCR: Polymerase Chain Reaction; DNA: Deoxy Ribonucleic Acid; CCU; Cardiac care unit, NICU; Neonatal Intensive Care Unit (NICU), PICU; Pediatric Intensive Care Unit, BICU; Burnt Intensive Care Unit

\section{Declarations}

\section{Acknowledgments}

We are grateful for the co-operation of the staff of the teaching and treatment hospitals for providing patients' information and the collection of the clinical isolates, as well as the honorable Vice-Chancellor of the Student Research Committee who supported this research project.

\section{Ethical approval and Consent to Participate}

This study directed in accordance with the Declaration of Helsinki, however printed informed consent form was provided by the patients or a close relative before hospitalization, and classifying information of each sample was kept secret. Also, this research approved by the ethics committee of Mazandaran University of Medical Sciences, Sari, Iran, with ethical code IR.MAZUMS.REC.1331.3065.

\section{Consent to Publication}

Not applicable.

\section{Competing interests}

The authors declared no conflict of interest.

\section{Availability of data and materials}


Data generated or analyzed during this study are included in this published article.

\section{Funding}

This research financially supported by Mazandaran University of Medical Sciences, Sari, Iran with Grant number 1331.

\section{Authors' Contribution:}

HRG and MA: Study concept and design; ZNB, RG and HRG: Acquisition of data; ZNB, MA and MBHS: Analysis and interpretation of data; ZNB: Drafting of manuscript; MA and HRG: Review of the article.

\section{References}

1. Diggle SP, Whiteley M. Microbe Profile: Pseudomonas aeruginosa: opportunistic pathogen and lab rat. Microbiology. 2020;166(1):30-3.

2. Chatterjee M, Anju C, Biswas L, Kumar VA, Mohan CG, Biswas R. Antibiotic resistance in Pseudomonas aeruginosa and alternative therapeutic options. International Journal of Medical Microbiology. 2016;306(1):4858.

3. Mohammadzadeh A, Mardaneh J, Ahmadi R, Adabi J. Evaluation of the virulence features and antibiotic resistance patterns of pathogenic Pseudomonas aeruginosa strains isolated from hospitalized patients in Gonabad, Iran. Archives of Pediatric Infectious Diseases. 2017;5(3):e41267.

4. Goli HR, Nahaei MR, Rezaee MA, Hasani A, Kafil HS, Aghazadeh M. Emergence of colistin resistant Pseudomonas aeruginosa at Tabriz hospitals, Iran. Iranian journal of microbiology. 2016;8(1):62.

5. Mirsalehian A, Kalantar-Neyestanaki D, Taherikalani M, Jabalameli F, Emaneini M. Determination of carbapenem resistance mechanism in clinical isolates of Pseudomonas aeruginosa isolated from burn patients, in Tehran, Iran. Journal of epidemiology and global health. 2017;7(3):155-9.

6. Amini A, Namvar AE. Antimicrobial Resistance Pattern and Presence of Beta-Lactamase Genes in Pseudomonas aeruginosa Strains Isolated from Hospitalized Patients, Babol-Iran. Journal of Medical Bacteriology. 2019;8(1, 2)):45-50.

7. Sedighi M, Hasanzadeh A, Safiri S, Syedi N, Mostafaei S, Faghri J. Detection of blaSPM-1 Metallo- $\beta$-Lactamase Gene in Imipenem-resistant Pseudomonas aeruginosa strains isolated from hospitalized patients in Isfahan Hospitals. Journal of Archives in Military Medicine. 2015;3(2).

8. Yousefi S, Farajnia S, Nahaei MR, Akhi MT, Ghotaslou R, Soroush MH, et al. Detection of metallo- $\beta$-lactamaseencoding genes among clinical isolates of Pseudomonas aeruginosa in northwest of Iran. Diagnostic microbiology and infectious disease. 2010;68(3):322-5.

9. Seok Y, Bae IK, Jeong SH, Kim SH, Lee H, Lee K. Dissemination of IMP-6 metallo- $\beta$-lactamase-producing Pseudomonas aeruginosa sequence type 235 in Korea. Journal of antimicrobial chemotherapy. 2011;66(12):2791-6.

10. Walsh TR, Toleman MA, Poirel L, Nordmann P. Metallo- $\beta$-lactamases: the quiet before the storm? Clinical microbiology reviews. 2005;18(2):306-25.

11. Wayne, PA: Clinical and Laboratory Standards Institute (CLSI): Performance standards for antimicrobial susceptibility testing: Twenty-seventh informational supplement, M100-S28. 2018. 
12. Kazeminezhad B, Rad AB, Gharib A, Zahedifard S. blaVIM and blalMPgenes detection in isolates of carbapenem resistant $P$. aeruginosa of hospitalized patients in two hospitals in Iran. Iranian journal of pathology. 2017;12(4):392.

13. Radan M, Moniri R, Khorshidi A, Gilasi H, Norouzi Z, Beigi F, et al. Emerging carbapenem-resistant Pseudomonas aeruginosa isolates carrying blalMP among burn patients in Isfahan, Iran. Archives of trauma research. 2016;5(3).

14. Cho HH, Kwon GC, Kim S, Koo SH. Distribution of pseudomonas-derived Cephalosporinase and Metallo- $\beta$ lactamases in Carbapenem-resistant Pseudomonas aeruginosa isolates from Korea. J Microbiol Biotechnol. 2015;25(7):1154-62.

15. Phillips PL, Schultz GS. Molecular mechanisms of biofilm infection: biofilm virulence factors. Advances in Wound Care. 2012;1(3):109-14.

16. Safari M, Alikhani MY, Arabestani MR, Kamali Kakhki R, Jafari R. Prevalence of Metallo- $\beta$-lactamases encoding genes among Pseudomonas aeruginosa strains isolated from the bedridden patients in the intensive care units. Avicenna J Clin Microbiol Infect. 2014;1(1):e19216.

17. Alikhani MY, Parsavash S, Arabestani MR, Hosseini SM. Prevalence of antibiotic resistance and class 1 integrons in clinical and environmental isolates of Pseudomonas aeruginosa. Avicenna J Clin Microbiol Infect. 2017;4.

18. Nikokar I, Tishayar A, Flakiyan Z, Alijani K, Rehana-Banisaeed S, Hossinpour M, et al. Antibiotic resistance and frequency of class 1 integrons among Pseudomonas aeruginosa, isolated from burn patients in Guilan, Iran. Iranian journal of microbiology. 2013;5(1):36.

19. Ismail SJ, Mahmoud SS. First detection of New Delhi metallo- $\beta$-lactamases variants (NDM-1, NDM-2) among Pseudomonas aeruginosa isolated from Iraqi hospitals. Iranian journal of microbiology. 2018;10(2):98.

20. Arunagiri K, Sekar B, Sangeetha G, John J. Detection and characterization of metallo- $\beta$-lactamases in Pseudomonas aeruginosa by phenotypic and molecular methods from clinical samples in a tertiary care hospital. West Indian Medical Journal. 2012;61(8):778-83.

21. Shakibaie MR, Shahcheraghi F, Hashemi A, Adeli NS. Detection of TEM, SHV and PER Type Extended-Spectrum ß-Lactamase Genes among Clinical Strains of Pseudomonas aeruginosa Isolated from Burnt Patients at Shafa-Hospital, Kerman, Iran. Iranian journal of basic medical sciences. 2008;11(2):104-11.

22. Attal R, Basak S, Mallick S, Bose S. Metallobetalactamase producing Pseudomonas aeruginosa: An emerging threat to clinicians. J Clin Diagn Res. 2010;4:2691-6.

23. Polotto M, Casella T, de Lucca Oliveira MG, Rúbio FG, Nogueira ML, de Almeida MT, et al. Detection of P. aeruginosa harboring bla CTX-M-2, bla GES1 and bla GES-5, bla IMP-1 and bla SPM-1 causing infections in Brazilian tertiary-care hospital. BMC infectious diseases. 2012;12(1):176.

24. Pitout JD, Chow BL, Gregson DB, Laupland KB, Elsayed S, Church DL. Molecular epidemiology of metallo- $\beta$ lactamase-producing Pseudomonas aeruginosa in the Calgary Health Region: emergence of VIM-2-producing isolates. Journal of clinical microbiology. 2007;45(2):294-8.

25. Zafer MM, Al-Agamy MH, El-Mahallawy HA, Amin MA, Ashour MSE-D. Antimicrobial resistance pattern and their beta-lactamase encoding genes among Pseudomonas aeruginosa strains isolated from cancer patients. BioMed research international. 2014;2014.

26. Xu Y, Niu H, Hu T, Zhang L, Su S, He H, et al. High Expression of Metallo- $\beta$-Lactamase Contributed to the Resistance to Carbapenem in Clinical Isolates of Pseudomonas aeruginosa from Baotou, China. Infection and drug resistance. 2020;13:35. 
27. Azimi A, Peymani A, Pour PK. Phenotypic and molecular detection of metallo- $\beta$-lactamase-producing Pseudomonas aeruginosa isolates from patients with burns in Tehran, Iran. Revista da Sociedade Brasileira de Medicina Tropical. 2018;51(5):610-5.

\section{Supplementary Files}

This is a list of supplementary files associated with this preprint. Click to download.

- SupplementaryFigures.pdf 